\title{
Silver Nanoparticle Deposition on Boron Nitride Surface ${ }^{\dagger}$
}

\section{Safa Polat ${ }^{1, *}$}

1 Department of Metallurgy and Materials Engineering, Karabuk University, Turkey; safapolat@karabuk.edu.tr (S.P.);

* Correspondence: safapolat@karabuk.edu.tr;

$\uparrow$ Presented at Materials Chemistry and Physics (Materials Chemistry 2020) - International e-Conference

Received: 16.09.2020; Revised: 20.09.2020; Accepted: 24.09.2020; Published: 27.09.2020

\begin{abstract}
Silver nanoparticles (AgNPs) are used in the functionalization of many materials. For this purpose, in our study, $\mathrm{Ag}$ (I) particles were deposited on boron nitride (BN) surfaces by using $\mathrm{AgNO}_{3}$ salt and $\mathrm{NaBH}_{4}$ reductants. A wet chemical reduction method, was used for this process. After precipitation, the solution was passed through filter paper and dried. The silver and boron nitride phases were confirmed by the XRD analysis of the solid mixture obtained. The analysis of the particles accumulated on the surface was examined using SEM images. As a result, it was understood that AgNPs particles did not form oxidic compounds and occurred on BN surfaces, but agglomerations were observed in some regions.
\end{abstract}

Keywords: silver nanoparticles; boron nitride; Tollens method.

(C) 2020 by the authors. This article is an open-access article distributed under the terms and conditions of the Creative Commons Attribution (CC BY) license (https://creativecommons.org/licenses/by/4.0/).

\section{Funding}

This research received no external funding.

\section{Acknowledgments}

I would like to thank Karabuk University's Materials Research Center.

\section{Conflicts of Interest}

The authors declare no conflict of interest. 